\title{
A COMUNICAÇÃO EM FÓRUNS DE UM CURSO A DISTÂNCIA DE FORMAÇÃO DE PROFESSORES PARA USO DE TDICS: ANÁLISE DA PRESENÇA DE ENSINO
}

\author{
Cibele Cecilio de Faria ROZENFELD ${ }^{1}$ \\ Fernanda Silva VELOSO ${ }^{2}$
}

RESUMO: A importância de inclusão de tecnologia digitais em sala de aula já vem sendo apontada por inúmeros autores no campo da educação e alguns deles preconizam que é por meio dessa inclusão que poderemos alcançar transformações em contextos escolares. Partindo desse pressuposto, este trabalho tem como objetivo apresentar um curso a distância oferecido para professores em formação continuada e inicial, voltado para o uso de tecnologias em sala de aula de língua estrangeira focalizando prioritariamente o papel dos professores formadores na mediação das discussões. Para tanto buscamos respaldo teórico em estudos que versam sobre cursos a distância (KENSKI, 2008), sobre ambientes virtuais (ARAÚJO JR.; MARQUESI, 2008), fóruns de discussão online e sobre comunidade de investigação e a presença de ensino (GARRISON; ANDERSON; ARCHER, 2000). Com respaldo nas teorias apresentadas, foram analisadas mensagens dos professores formadores ao longo de um curso oferecido na modalidade a distância para professores em formação continuada e inicial, identificando as marcas da presença de ensino e apontando para as mediações adequadas e/ou possíveis lacunas. Os resultados apontam que o professor deve estar cada vez mais atento aos tipos de feedbacks que fornece e à presença de ensino no sentido de Garrison e colaboradores (2000, 2001).

PALAVRAS-CHAVE: Educação à distância. Fóruns online. Formação de professores.

\section{Introdução}

Muito tem se alertado hoje para o fato de que a escola, tradicionalmente constituída, é hoje pouco atraente para o alunado que nela estuda. Ela é vista frequentemente como compartimentada, os conteúdos trabalhados são apresentados de forma desconectada da vida cotidiana do aluno, os professores estão desmotivados, a infraestrutura está comprometida, fatos que geram grande distanciamento entre a escola necessária na sociedade do conhecimento e a real (MORAN, 2007).

Diante de tal fato, estudiosos apontam de forma recorrente para a grande

\footnotetext{
${ }^{1}$ Professora no Programa de Pós-Graduação em Linguística e Língua Portuguesa e na graduação. UNESP - Universidade Estadual Paulista. Faculdade de Ciências e Letras - Departamento de Linguística. Araraquara - SP - Brasil. 14800-901 - cibeleroz@fclar.unesp.br.

${ }^{2}$ Professora de Metodologia e Prática de Ensino de Línguas Estrangeiras Modernas Neolatinas. UFPR Universidade Federal do Paraná. Curitiba - PR - Brasil. 80.060-000 - fernandaveloso@ufpr.br.
} 
necessidade de mudanças estruturais na educação, como, por exemplo, Kenski (2008), que afirma ser preciso repensarmos as formas como ensinamos e como nos relacionamos com o conhecimento, a fim de podermos acompanhar o ritmo em que a sociedade se encontra na atualidade. Ainda segunda essa autora, é necessário integrar o espaço digital em sala de aula, pois o mundo físico e o virtual não se opõem, mas se complementam, integram, combinam numa interação cada vez maior, contínua, inseparável.

A escola deve caminhar para ser um espaço onde se aprende de novas maneiras, ajudando seus alunos a aprender de forma mais integral e continuamente. Com as escolas cada vez mais conectadas à internet, os papéis do educador se modificam consideravelmente, se multiplicam, complementam, exigindo dos professores grande capacidade de adaptação, criatividade diante de novas situações, propostas e atividades. Os professores precisam aprender a "trabalhar com tecnologias simples e sofisticadas" (KENSKI, 2008, p.35), se adaptar às suas condições tecnológicas institucionais, ter flexibilidade para adaptar-se a situações muito diferentes e sensibilidade para escolher as melhores soluções possíveis tendo em vista seu grupo de alunos.

Para que ocorra uma mudança no cenário educacional, no entanto, o simples uso de novas tecnologias não basta. É necessário que haja um professor mediador, orientador da aprendizagem e, assim, a mediação pedagógica assume papel fundamental em um processo inovador de ensino e aprendizagem. A partir disso, é fundamental que formação inicial e formação continuada de professores sejam repensadas.

Diante do exposto, este trabalho buscará descrever aspectos de um curso a distância, oferecido para professores em formação inicial e continuada, que focalizou o uso de tecnologias (novas e velhas) em sala de aula de língua estrangeira. O objetivo principal do programa foi incentivar os professores para o uso de tecnologias - das novas às velhas - em sala de aula de língua estrangeira em contexto contemporâneo, enfatizando a importância e a potencialidade das TDICs (Tecnologias Digitais de Informação e Comunicação) para o ensino e aprendizagem de línguas e apontando para algumas possibilidades de aplicação prática.

Nosso foco recairá especialmente na Presença de Ensino (GARRISON, ANDERSON, 2003), ou seja, no papel dos professores formadores no desenvolvimento do pensamento crítico dos participantes e na promoção de Presença Social ${ }^{3}$.

${ }^{3}$ Os conceitos Presença de Ensino e Social serão apresentados no próximo item. 


\section{O processo de ensino e aprendizagem em ambientes virtuais}

O processo de ensinar é, conforme Litto e Formiga (2008), muito mais que a mera transmissão de informações: é refletir, ouvir, entender, respeitar, aceitar, facilitar, provocar, motivar, promover reflexão, mediar, interagir por meio das TDICs, e o processo de aprender ocorre não somente em espaços institucionais, mas também além deles.

Valente e Bustamante (2009) advogam, nesse sentido, que o professor não é mais o centro, o detentor de saberes e não deve dar as costas às transformações educacionais decorrentes do uso das novas tecnologias e à expansão das fronteiras. Ao contrário, ele deve entender o seu papel fundamental de guia, orientador e/ou de “animador de interações”. (VALENTE; BUSTAMANTE, 2009).

O deslocamento do papel do professor do centro de ensino e aprendizagem favorece a aprendizagem colaborativa, a ajuda mútua, a troca de informações, a reflexão, o trabalho cooperativo, etc. Porém, para que isso aconteça, devem ser criadas as condições adequadas e nesse aspecto é revelado novamente o importante papel de mediador do professor, provocador e motivador das interações, saindo do centro das interações, dando espaço e voz aos participantes.

Nessa perspectiva, consideramos que o maior contato entre professor e alunos participantes de um curso virtual pode ocorrer também em Ambientes Virtuais de Aprendizagem (AVA).

Um Ambiente Virtual de Aprendizagem é definido por Araújo Jr. e Marquesi (2008) como aquele que simula espaços presenciais de aprendizagem com o uso da TIC. Os AVAs permitem troca de mensagens, estando os participantes em diferentes localidades ou tempos, troca de significado sobre determinado assunto por um número variável de participantes, em diversos contextos, muitas vezes em culturas distintas (ARAÚJO JR.; MARQUESI, 2008).

Todavia, Araújo Júnior e Marquesi (ARAÚJO JR.; MARQUESI, 2008, p.363), alertam para o fato de que "é importante assegurar a interação em situações virtuais", pois ela irá garantir a "presença social", enquanto na situação presencial, a interação se inicia pela própria presença física, mesmo que se dê apenas por meio do silêncio, dos gestos e de olhares. 
Nessa perspectiva, reiteramos a grande importância do professor na elaboração de atividades, na seleção de recursos e na mediação pedagógica durante as interações. Seu papel no sucesso ou fracasso do processo de ensino e aprendizagem em um AVA poderá estar diretamente relacionado com o tipo de mediação realizada.

Garrison, Anderson e Archer (2000) propõem o modelo de "comunidade de investigação" como possibilidade de análise da comunicação mediada por computador, visto que ele abarca tanto a perspectiva do aluno (presença cognitiva), quanto a do professor (presença de ensino) e da interação (presença social). O modelo dos autores baseou-se na comunicação de participantes de uma comunidade de investigação em fóruns de discussão.

O "fórum de discussão" é uma ferramenta digital comumente utilizada em AVAs com o objetivo de promover debates e ocupa um papel central no âmbito deste trabalho. Seu funcionamento baseia-se na execução de alguns passos gerais: abre-se um fórum em um AVA, tendo em vista um tema a ser discutido e objetivos específicos, e nele serão abertos tópicos (subtemas). Nos fóruns gerais os participantes do ambiente podem responder às postagens de colegas, do professor ou ainda abrir um novo tema (tópico) de discussão. Ele possibilita, dessa forma, a ocorrência de interações alunoaluno e aluno-professor, em tempos distintos, em diferentes espaços, ou seja, a realização de atividades assíncronas.

Nos ambientes virtuais de aprendizagem, os fóruns são de grande utilidade para tirar dúvidas, trocar informações, para a discussão de temas específicos e para a troca de experiência entre os participantes.

Pode-se afirmar que os fóruns online são caracterizados fortemente pela marca dialógica que acompanham os variados discursos produzidos por seus participantes e constituem-se em um novo gênero discursivo de característica híbrida: com traços da escrita e da oralidade ${ }^{4}$.

Para o desenvolvimento deste trabalho, apoiamo-nos fortemente em pressupostos teóricos dos autores Garrison, Anderson e Archer (2000), que apontam para a necessidade de se investigar os efeitos da Comunicação Mediada por Computador (doravante CMC), bem como buscam a compreensão das formas de interação e dos produtos dos participantes engajados no uso da CMC para fins educacionais.

\footnotetext{
${ }^{4}$ Ressaltamos que "oralidade" aqui não se refere à materialidade. O termo é tomado tal como postulado na literatura de LA, fazendo referência a situação prototípica de diálogo oral informal.
} 
Nessa perspectiva, Garrison e colaboradores (2001, 2003) elaboraram o modelo conceitual de Comunidade de Investigação, que busca categorizar os tipos de interação em fóruns utilizados em instituições de ensino superior.

Os pesquisadores identificaram os elementos considerados requisitos cruciais para uma experiência educacional bem sucedida em contexto virtual e a elaboração do modelo parte da premissa de que a linguagem escrita e a falada possuem diferentes efeitos no processo do pensamento, sendo necessário salientar as características da comunicação escrita voltada para o discurso crítico. De acordo com os autores, quando o objetivo é facilitar o pensamento acerca de temas complexos e a aprendizagem significativa, o uso da linguagem escrita pode ser determinante.

Com base em tais premissas, Garrison e colaboradores (2000, 2001, 2003) advogam que a comunidade de investigação para construção do conhecimento e desenvolvimento de pensamento crítico apenas pode atingir seus objetivos se incluir três elementos essenciais: presença social, presença de ensino e presença cognitiva.

A presença de ensino consiste no papel do professor na promoção do desenvolvimento da presença social e cognitiva, por meio do manejo das ferramentas e gestão do ambiente. Para que ela ocorra é fundamental que estejam envolvidos três campos essenciais: o design e organização do ambiente (Instrucional design and organization), a facilitação do discurso (Facilitating discourse) e a instrução direta (Direct Instruction) (GARRISON; ANDERSON, 2003; GARRISON; ANDERSON; ARCHER, 2001).

Garrison, Anderson e Archer (2001) elaboraram três quadros descritivos referentes a esses campos de atividades da presença de ensino, que são sintetizados na Tabela 1:

Tabela 1 - Funções da presença de ensino e seus indicadores

\begin{tabular}{|c|l|}
\hline Funções & Indicadores \\
\hline $\begin{array}{c}\text { Design e } \\
\text { organização }\end{array}$ & $\begin{array}{l}\text {-definição do currículo: apresentação do programa e do planejamento das } \\
\text { atividades, por exemplo, apresentando as discussões que serão realizadas; } \\
\text {-definição de métodos, por exemplo, explicitando a maneira como devem } \\
\text { ocorrer os debates; } \\
\text {-estabelecimento de parâmetros de tempo, por exemplo, estipulando prazos } \\
\text { para a realização das atividades; } \\
\text {-utilização eficiente das mídias, por exemplo, explicitando como devem } \\
\text { ocorrer as postagens em fóruns; } \\
\text {-estabelecimento da netiqueta, por exemplo, dando instruções acerca do } \\
\text { tamanho das mensagens, e tipo de linguagem na interação. } \\
\text {-elaboração de comentários gerais sobre conteúdos do curso }\end{array}$ \\
\hline
\end{tabular}




\begin{tabular}{|c|c|}
\hline $\begin{array}{l}\text { Facilitação } \\
\text { do discurso }\end{array}$ & $\begin{array}{l}\text {-Identificação de áreas de concordância e discordância entre os participantes; } \\
\text {-busca por consenso e compreensão; } \\
\text {-mensagens de encorajamento, compreensão ou reforço das contribuições dos } \\
\text { participantes; } \\
\text {-Estabelecimento de clima propício para a aprendizagem; } \\
\text {-Direcionamento de comentários; } \\
\text {-Avaliação da eficácia do processo; }\end{array}$ \\
\hline $\begin{array}{c}\text { Instrução } \\
\text { direta }\end{array}$ & $\begin{array}{l}\text {-Apresentação de conteúdos ou questionamentos; } \\
\text {-Foco na discussão de assuntos específicos; } \\
\text {-Apresentação de síntese da discussão; } \\
\text {-Confirmação do entendimento por meio de feedbacks avaliativos e } \\
\text { exploratórios; } \\
\text {-Diagnóstico de mal-entendidos; } \\
\text {-Apresentação de informações de outras fontes, como por exemplo, de um } \\
\text { livro texto, jornal, internet, experiências pessoais; } \\
\text {-Auxílio em problemas técnicos. }\end{array}$ \\
\hline
\end{tabular}

Fonte: Elaboração própria baseado em Garrison, Anderson e Archer (2001).

\section{Metodologia}

Com o intuito de analisar a presença de ensino na comunicação mediada por computador, analisamos as mensagens de um curso a distância de formação de professores, oferecido como curso de extensão para professores em formação inicial e continuada de línguas estrangeiras. O curso teve duração de nove semanas, contou com a participação inicial de 32 participantes, sendo 17 deles em formação inicial e 15 em formação continuada. O curso foi elaborado e mediado por três professores formadores, que dividiram funções ao longo do curso. O objetivo do curso foi abordar o uso das Tecnologias Digitais de Informação e Comunicação (TDICs) que podem ser utilizadas em sala de aula de LE (Título do curso: "O uso de novas e velhas tecnologias em sala de aula de língua estrangeira" - NoVeTeLE). Para tanto, ele foi organizado em nove módulos distintos, conforme apresentamos na Tabela 2:

Tabela 2 - Módulos do curso NoVeTeLE

\begin{tabular}{|c|l|c|l|}
\hline $\begin{array}{c}\text { Módulo } \\
\text { número }\end{array}$ & Título & $\begin{array}{l}\text { Módulo } \\
\text { número }\end{array}$ & \multicolumn{2}{|c|}{ Título } \\
\hline $\mathbf{1}$ & $\begin{array}{l}\text { Apresentação do grupo - conhecendo } \\
\text { o ambiente do curso }\end{array}$ & $\mathbf{6}$ & $\begin{array}{l}\text { Banco de ideias: ferramentas } \\
\text { digitais para o ensino e } \\
\text { aprendizagem de LE }\end{array}$ \\
\hline $\mathbf{2}$ & Somos antes de tudo educadores & $\mathbf{7}$ & $\begin{array}{l}\text { Planejamento de aulas: usando } \\
\text { TDICs em sala de aula }\end{array}$ \\
\hline
\end{tabular}




\begin{tabular}{|c|l|c|l|}
\hline $\mathbf{3}$ & $\begin{array}{l}\text { Do códex à cibercultura: sobre novas e } \\
\text { velhas tecnologias }\end{array}$ & $\mathbf{8}$ & $\begin{array}{l}\text { Elaboração de trabalhos de } \\
\text { finalização de curso }\end{array}$ \\
\hline $\mathbf{4}$ & $\begin{array}{l}\text { As Tecnologias Digitais de } \\
\text { Informação e Comunicação (TDIC) } \\
\text { em sala de aula de LE }\end{array}$ & $\mathbf{9}$ & Avaliação do curso \\
\hline $\mathbf{5}$ & $\begin{array}{l}\text { Objetos de Aprendizagem: } \\
\text { pesquisando o termo e os repositórios }\end{array}$ & & \\
\hline
\end{tabular}

Fonte: Elaboração própria.

\section{Análise e discussão dos dados}

Tendo em visto o exposto anteriormente, a fim de analisarmos os dados, buscamos respaldo teórico na noção de Presença de Ensino de Garrison e colaboradores, suas funções e indicadores.

Encontramos em nossos dados várias mensagens dos professores formadores com a função de instrução direta para a solução de problemas técnicos, como, por exemplo:

R: Oi, Professora! [...] o que se refere a grupos, clico onde? bjos, grata

Professor 1: Veja como selecionar seu grupo na figura em JPG e editar o texto (por exemplo, se for um participante do grupo M3.Grupo A: [em anexo à mensagem encontrava-se imagem de Print screen da tela com ambiente do curso, focalizando a atividade em foco e com destaque ao local onde os cursistas deveriam clicar para encontrar seus grupos].

A instrução direta é marcada ainda em sínteses sobre as temáticas abordadas, apresentadas pelos docentes ao final de cada módulo.

Foi possível reconhecer ainda mensagens dos professores com função de design

e organização na explicitação da forma como as atividades deveriam ser realizadas,

bem como na estipulação de prazo para o cumprimento das tarefas:

Professor 1: Já encontra-se aberto o módulo 5. Quem não finalizou as atividades do módulo 4, ainda poderá fazê-lo até sexta-feira, ok? Obrigada!abçs

Professor 2: Obrigada P1! Como temos apenas 7 dias para realizar todas as tarefas deste módulo, acho extremamente importante que comecemos o mais rápido possível a discussão no fórum "Discussão das questões sobre o texto" sobre as questões relacionadas ao texto "O que são Objetos de Aprendizagem?". Só assim teremos tempo para discutir todos os tópicos criados por vocês e em seguida participar dos 
outros dois fóruns: "Vídeo: Objetos de Aprendizagem" e "Análise de OAs nos diferentes repositório" Quem começa? Abraços e boa semana a todos!

Notamos em várias das mensagens dos professores formadores a valorização da contribuição e do trabalho dos participantes, fato relacionado à função de facilitação do discurso, como no caso das mensagens a seguir, na qual a participante faz uma sugestão ao professor e este a acata e a valoriza:

B:Professora, eu queria saber se você poderia deixar disponíveis os textos dos módulos anteriores, porque as vezes queremos citar algum e eles já não estão mais disponíveis.

Professor 1: ok, B., acho uma boa ideia.....já abri novamente os textos e os vídeos, deixei apenas as atividades fechadas. Obrigada pela sugestão!.

Abçs

Também em:

Professor 1: pessoal, vejo que vocês estão elaborando a síntese do vídeo corretamente, em seus respectivos grupos M4.GrupoX. Perfeito!! As sínteses também estão ficando ótimas....

Abçs

Ou ainda em:

Professor 3: Nossa I., eu não sabia dessa referência, vou conferir.Abraços

Nota-se a valorização da discussão dos alunos, propondo ainda a leitura de estudos e teorias:

Professor1: M. e S, está sendo muito bom acompanhar o diálogo de vocês acerca de questões e teorias tão importantes....o que os demais colegas de grupo acham disso tudo??? vou aguardar....

Professor 1: S, você citou Ken Robinson e a importância que dá à criatividade no processo educacional...realmente...e me lembrei de uma corrente pedagógica, com base na Antroposofia de Rudolf Steiner, a Pedagogia Waldorf....você já ouviu falar? Se não conhece, pesquise e verá que é uma pedagogia que valoriza muito o ser humano em toda a sua potencialidade e criatividade....é um trabaho maravilhoso! []s

No exemplo acima, o professor, além de reforçar as contribuições das duas alunas, convida os outros participantes a também participar da interação. A indicação de estudos é uma das marcas da presença de ensino. Notamos, porém, que tal procedimento não é exclusivo do professor: a presença de ensino nos fóruns não é necessariamente 
desempenhada pelo professor, mas outros participantes também podem contribuir com indicação de material, esclarecimentos, como no exemplo a seguir:

L: Olá pessoal, na discussão do módulo 2 eu indiquei, para o meu grupo, alguns vídeos sobre educação que acho muito interessantes. Aqui estão os vídeos, caso vocês se interessem, ok? Boa semana! [...]

Professor 2: Muito obrigada, L., por compartilhar o material.....acho que devemos mesmo usar o espaço do nosso curso para compartilhar boas ideias, não acham:?abçs

Em algumas postagens desses mesmos professores formadores encontramos ainda apresentação de informações com base em suas experiências pessoais e profissionais:

Professor 2: Gostaria de compartilhar com vocês uma atividade que utilizei em um curso de italiano a distância e que de certa forma fazia uso da rede social "Facebook" [...]

E então o professor descreve a atividade realizada por ele na rede social. Também observamos tal fato em:

Professor 2: eu também costumava usar muitos filmes em minhas aulas quando trabalhava no CEL. No entanto, só descobri recentemente que a SEE-SP enviou a todas as escolas públicas um material bem interessante sobre o cinema.

Além de citar e discutir a teoria estudada ao longo do curso, os professores formadores expõem também suas experiências profissionais com o intuito de ilustrar suas opiniões, bem como de contribuir para um ambiente propício de aprendizagem, na medida em que se colocam também na condição de professores em formação continuada.

\section{Considerações finais}

A comunicação mediada por computador ainda vem sendo explorada e demonstra ser um campo que necessita ainda desenvolvimento de novos estudos. Do ponto de vista do aluno, notamos que ele muitas vezes não está adaptado a essa nova forma de aprender, ao aprender a aprender, pois não vem de uma cultura de ensino e 
aprendizagem, na qual a autonomia lhe é conferida. Nesse sentido, encontramos poucas mensagens dos alunos voltadas para o trabalho colaborativo.

Do ponto de vista do professor, ele e sua forma de mediação poderão ser a chave para o sucesso ou fracasso do processo de aprendizagem. O professor como mediador e provocador está constantemente diante de incertezas e de desafios acerca da forma de apresentação de conteúdos, de sistematização do conhecimento, de exploração de espaços virtuais e recursos virtuais e avaliação formativa, ou ainda, acerca da melhor forma de se relacionar com e responder ao aluno.

Diante do exposto, faz-se necessário que o professor, principalmente aquele da educação a distância, fique atento aos tipos de feedbacks que fornece e à presença de ensino no sentido de Garrison e colaboradores (2000, 2001). Para tanto, como apontado anteriormente é importante fornecer feedbacks relacionados ao design e organização do ambiente, à facilitação do discurso e à instrução direta, ao logo de todas as atividades e de todo o curso (GARRISON; ANDERSON, 2003; GARRISON; ANDERSON; ARCHER, 2001).

\section{FORUM COMMUNICATION IN A DISTANCE PRESERVICE AND IN-SERVICE TEACHER EDUCATION FOR THE USE OF DIGITAL TECHNOLOGIES OF INFORMATION AND COMMUNICATION: ANALYSES OF TEACHING PRESENCE}

ABSTRACT: The importance of the inclusion of digital technology in the classroom has already been pointed out by numerous authors in the educational field and some of them herald that it is through this inclusion that we can achieve transformations in school settings. Based on this assumption, this paper aims to present a distance learning course offered to in service and preservice teachers, focused on the use of technology in foreign language classroom primarily focusing on the role of teacher educators in mediating discussions. For this we sought theoretical support in studies which deal with distance courses (KENSKI, 2008), about virtual environments (ARAÚJO and MARQUESI, 2008), online discussion forums and investigation community and teaching presence (GARRISON, ANDERSON and ARCHER, 2000). Based on the previous theories presented, teacher educator's messages were analyzed during a distance course offered to teachers in continuing and initial training, identifying marks of teaching presence and pointing to appropriate mediations and/or possible gaps. The results indicate that the teacher must be even more aware of the types of feedback that are provided and of the teaching presence mentioned by Garrison and colleagues (2000, 2001).

KEYWORDS: Distance education. Online forums. Teacher education. 


\section{REFERÊNCIAS}

ARAÚJO JÚNIOR, C. F.; MARQUESI, S. C. Atividades em ambientes virtuais de aprendizagem: parâmetros de qualidade. In: LITTO, F. M.; FORMIGA, M. (Org.). Educação à Distância: o estado da arte. São Paulo: Pearson Education, 2008. p.358368.

GARRISON, D. R.; ANDERSON, T. E-Learning in the 21st Century: A Framework for Research and Practice. London; New York: Routledge Falmer, 2003.

GARRISON, R.; ANDERSON, T.; ARCHER, W. Critical inquiry in a Text-Based Environment: Computer conferencing in higher education. Internet and Higher Education, Oxford, v.2, n.2-3, p.1-14, 2000.

.Critical thinking, cognitive presence and computer conferencing in distance education. American Journal of Distance Education, Philadelphia, v.15, n.1, p.7-23, 2001. Disponível em:

$<$ http://cde.athabascau.ca/coi_site/documents/Garrison_Anderson_Archer_CogPres_Fin al.pdf>. Acesso em 27/02/2015.

KENSKI, V. M. Tecnologias e ensino presencial e a distância. Campinas: Papirus, 2008.

LITTO, F. M.; FORMIGA, M. (Org.). Educação à Distância: o estado da arte. São Paulo: Pearson Education, 2008.

MORAN, J. M. A educação que desejamos: novos desafios e como chegar lá. Campinas: Papirus, 2007.

VALENTE, J. A.; BUSTAMANTE, S. B. V. Educação à Distância: Prática e Formação do Profissional Reflexivo. São Paulo: Avercamp, 2009. 